УДК 622.276 .72

\title{
ТЕХНОЛОГИИ УДАЛЕНИЯ АСФАЛЬТОСМОЛОПАРАФИНОВЫХ ОТЛОЖЕНИЙ ИЗ НЕФТЕДОБЫВАЮЩИХ СКВАЖИН С ПОМОЩЬЮ РАСТВОРИТЕЛЕЙ
}

\author{
Денисламов Ильдар Зафирович1, \\ denislamoviz@mail.ru
}

\author{
Имамутдинова Аделина Алтафовна 1 , \\ adelina.imamutdinova99@mail.ru
}

Самушкова Элина Сергеевна', elinkasamushkova@mail.ru

1 Уфимский государственный нефтяной технический университет, Россия, 450062, г. Уфа, ул. Космонавтов, 1.

\begin{abstract}
Актуальность исследования следует из того, что на многих месторождениях добывается остаточная несрть повышенной плотности со значительным содержанием тяжелых компонентов, прежде всего асфральтенов и смол. По многим несртяным компаниям наблюдается рост добывающего фонда скважин, эксплуатация которых осложнена формированием асфральтосмолопарафриновых отложений.

Цель: выполнить обзорный анализ применения методов предупреждения и удаления асфральтосмолопарафиновых отложений на нефртяных месторождениях и разработать компоновку подземного оборудования скважин, основанную на применении реагентной трубки для доставки реагентов любого типа и дозировки на прием электроцентробежного насоса.

Объектом исследования являются методы удаления асфральтосмолопарафииновых отложений, основанные на применении органических растворителей, которые доставляются на прием глубинного насоса по межтрубному пространству скважины и по колонне лифртовых труб. В статье рассмотрены все возможные варианты доставки реагента: два вида по межтрубному пространству и столько же по колонне подъемных труб.

Методы исследования основаны на законах физической гидродинамики, индикаторных (реперных) технологий и сравнительном анализе технических новшеств в отечественном и мировом опьте борьбы со скважинными отложениями.

Результаты. Обоснована необходимость расположения реагентной трубки внутри колонны лифртовых труб; разработан дизайн реагентной трубки и насосного оборудования, обеспечивающий поступление реагента любого типа товарного качества на прием электроцентробежного насоса; предложен способ определения степени заполнения лифттовых труб с помощью промежуточной - реперной - жидкости со свойствами, отличными от скважинной продукции и органического растворителя; для объяснения результатов фракторного анализа успешности доставки растворителя по межтрубному пространству скважины с асфральтосмолопарафиновыми отложениями приводится теория двойного течения нефти в межтрубном пространстве.
\end{abstract}

\section{Ключевые слова:}

Скважина, реагентная трубка, ингибитор, датчик давления, плотность, асфальтосмолопарафиновые отложения, межтрубное пространство, реперная жидкость, органический растворитель.

\section{Введение}

Наличие асфальтосмолопарафиновых отложений (АСПО) внутри колонны лифтовых труб скважин, на приемном фильтре глубинного насоса и в его полости значительно снижает производительность насоса любого типа, из-за отложений сокращается и межремонтный период эксплуатации скважинного оборудования. На большинстве нефтяных месторождений число скважин с АСПО составляет $15-25 \%$ от общего фонда добывающих скважин, но такого рода осложнения могут наблюдаться и на 44-59 \% нефтедобывающих скважин некоторых месторождений страны $[1,2]$. Для обслуживания таких скважин инженерно-техническим персоналом предприятий разрабатывается целый комплекс мероприятий, включающий ингибирование парафинообразования и удаление отложений наиболее экономически привлекательным способом.

Руководящими производственными документами нефтяных компаний предусмотрена подача ингибитора на скважинах, эксплуатация которых осложнена формированием АСПО в глубинно-насосном обору- довании. В статье [3] указаны новые типы химических ингибиторов АСПО и в краткой форме изложены факторы, определяющие эффективность ингибиторов:

1. Ламинарный режим движения скважинной продукции благоприятен для адсорбции асфальтенов и смол, а при турбулентном режиме течения формируются отложения с высоким содержанием парафина.

2. Ингибиторы парафинообразования показывают большую эффективность при низких температуpax движения нефти в промысловом оборудовании.

3. Содержание высокомолекулярных углеводородов парафинового ряда в АСПО влияет не только на температуру плавления отложений, но и на эффективность применения ингибиторов парафинообразования.

4. Длина боковых ответвлений углеводородной цепи полимерного ингибитора должна соответствовать средней длине молекулы парафинов. Изменение этой длины ведет к снижению эффекта ингибиро- 
вания процесса агломерации кристаллов парафина в объеме нефти.

5. Доля органического растворителя в полимерном ингибиторе не может быть ниже определенной величины, иначе происходит скручивание цепи полимера и его малой эффективности блокировки кристаллов парафинов.

Исследования авторов [4] показывают, что формирование отложений парафина можно предотвратить или значительно замедлить с помощью химических поверхностно-активных веществ с функцией диспергации парафинов в объеме нефти. Диспергаторы непрерывно подают в скважину или их дозируют в пластовую продукцию через определенные промежутки времени. Выбор использования периодической или непрерывной обработки зависит от типа и количества скважин, требующих обработки. В работе [5] предложена технология непрерывного введения ингибитора парафинообразования в скважинную продукцию на расчетной глубине, где образование твердого парафина еще не наблюдалось.

Опыт эксплуатации осложненных скважин показывает, что дозировка на прием глубинного насоса ингибитора предупреждает или снижает интенсивность парафинообразования не во всех скважинах даже в пределах одного нефтяного месторождения. Такое положение в нефтедобыче можно объяснить различным компонентным составом добываемой нефти по скважинам месторождения и тем, что универсальные ингибиторы до сих пор не созданы [6-13]. В частности, в работе [13] отмечается, что ингибиторы АСПО показывают лучший эффект в нефти, в которой содержание высокомолекулярных углеводородов (парафины $\mathrm{C}_{24}+$ ) не превышает 39 \%. Авторы статьи [14] дополняют эти исследования утверждением, что ингибиторы снижают парафинообразование в углеводородах с низкой молекулярной массой, но влияют незначительно на парафины с высокой молекулярной массой $\left(\mathrm{C}_{35}-\mathrm{C}_{44}\right)$.

Сформировавшиеся отложения можно удалить несколькими способами:

- путем подъема колонны лифтовых труб и подачи в трубы на устье скважины пара высокой температуры;

- периодическим скребкованием колонны насоснокомпрессорных труб устройствами различных конструкций;

- тепловым воздействием на отложения;

- диспергированием и растворением отложений органическим растворителем.

Спускоподъемные операции глубинного оборудования скважин - это дорогостоящая процедура для нефтегазодобывающего предприятия, выбытие скважины из процесса воздействия на продуктивный пласт на 3-4 дня, снижение фазовой проницаемости призабойной зоны пласта по нефти на несколько дней из-за попадания в пласт задавочного раствора. Извлеченные на поверхность асфальтосмолопарафиновые вещества (АСПВ) необходимо должным образом утилизировать или отправить в шламонакопитель для безопасного хранения.
Периодическое движение скребка вверх и вниз обеспечивает предупреждение или удаление тонкого слоя АСПВ с поверхности колонны труб и поддержание работоспособности глубинного насоса на должном уровне. Проблему эксплуатации скважин со штанговыми плунжерными насосами в ПАО «Татнефть» имени В.Д. Шашина решили установкой на большую часть фонда таких скважин штанговых скребков-центраторов [9].

Тепловые методы сегодня широко используются на промыслах и $[1,2,15,16]$, как правило, реализуются закачкой горячей нефти или воды в межтрубное пространство скважины. Расплавленные отложения внутри лифтовых труб выносятся восходящим потоком скважинной продукции и вновь обретают твердую форму на определенном расстоянии от скважины в трубопроводе системы нефтесбора или емкостном оборудовании [17]. К тому же диспергированные частички АСПВ являются стабилизаторами водонефтяной эмульсии и могут участвовать в формировании промежуточных трудноразрушаемых слоев нефти и воды в горизонтальных отстойниках и вертикальных резервуарах. Авторы статьи [18] отмечают, что тепловые методы удаления АСПО имеют непродолжительную эффективность и применимы лишь в ограниченных скважинных условиях.

Применение органических растворителей на осложненных скважинах не имеет таких отрицательных последствий, поэтому, несмотря на их высокую стоимость, объемы их потребления в нефтяных компаниях не снижаются [16, 19, 20]. Стимулирующим фактором для массового использования растворителей является и то, что компаундирование алифатических углеводородов ароматическими растворителями и поверхностно-активными веществами заметно повышает растворяющую и диспергирующую способность подобных реагентов [21].

Существует несколько способов доставки органического растворителя в скважинную зону с отложениями. Рассмотрим достоинства и недостатки известных технологий для выработки технических решений по созданию дополнительного скважинного оборудования для скважин с АСПО.

Организация доставки растворителя

по межтрубному пространству скважин

Как и любой реагент или технологическая жидкость, растворитель АСПО может быть доставлен на прием глубинного насоса по межтрубному пространству (МП) двумя способами:

1) продвижением по кольцевому пространству скважины самотеком или с помощью продавливания иной жидкостью, в качестве которой может быть скважинная продукция (циркуляция жидкости из колонны лифтовых труб в МП или нефть, закачиваемая под давлением передвижным насосным агрегатом типа ЦА-320);

2) по реагентной трубке типа колтюбинговой на стационарной основе. В отличие от известной капиллярной трубки, широко используемой в подразделениях ПАО «Башнефть» [22] и других компаниях 
[1, 23-25], реагентная трубка имеет внутренний диаметр до 15 мм. Несмотря на наличие защитной бронированной оболочки при спускоподъемных операциях реагентная и капиллярная трубки могут быть повреждены и смяты под действием нескольких тонн колонны насосно-компрессорных труб [10, 26].

На нефтяных промыслах органический растворитель часто заливают в межтрубное пространство самотеком, не применяя насосный агрегат ЦА-320, после снижения давления в МП до атмосферного. Результаты обработок скважин с применением насосной установки и самотеком приведены в статье [27]. Проведенный в статье статистический анализ показывает, что лишь 60-70 \% из более чем 2000 обработок были успешными по критериям: повышение дебита жидкости и снижение нагрузок на глубинный насос. С одной стороны, авторы статьи [28] отмечают, что при движении растворителя вниз по межтрубному пространству происходит смыв АСПВ с внешней стороны колонны НКТ и внутренней поверхности обсадной колонны и насыщение её частичками растворителя, вследствие чего снижается растворяющая способность реагента при входе в глубинный насос. С другой стороны, факторный анализ, проведенный в работе [27], показал, что из пяти скважинных факторов, учитываемых при выборе скважины с АСПО для обработки растворителем, высота жидкости в МП над насосом является наименее значимым. Данное противоречие можно объяснить теорией «двойного течения» [29], существующего в межтрубном пространстве скважины в интервале от насоса до динамического уровня жидкости. По мнению авторов, легкая нефть с газом поднимается выше насоса и в зоне уровня жидкости отдает попутный нефтяной газ в газовую среду, повышая её давление. Нефть без газа, имея большую плотность, тонет в восходящем потоке легкой нефти и достигает приемных отверстий насоса В работах $[30,31]$ выполнена оценка плотности газожидкостного состава в МП в интервале от динамического уровня жидкости до насоса - для скважин с малой обводненностью плотность может варьировать

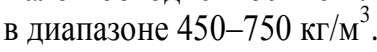

Приведенная теория объясняет не только наличие положительного действия от доставки органического растворителя в МП самотеком, но и эффективность таких скважинных процедур, как разовые или постоянные подачи с устья скважины в МП деэмульгаторов, нейтрализаторов сероводорода, ингибиторов коррозии и парафинообразования, имеющих значительно большую плотность, чем газожидкостной состав в межтрубном пространстве.

\section{Организация доставки растворителя} по колонне насосно-компрессорных труб

Закачка растворителя или горячей нефти в колонну НКТ организуется, как правило, двумя способами:

1. Над насосом отсутствует обратный клапан, или имеется перепускной клапан типа КОТ-93 [32, 33]. Клапан при создании значительного перепада давления позволяет организовать движение жид- кости в сторону глубинного насоса, тем самым заполнять колонну НКТ реагентом. Объем растворителя рассчитывают с учетом прогнозной толщины отложений с тем, чтобы реагент дошел до электроцентробежного насоса, а также промыл его рабочие колеса, направляющие аппараты и приемные щелевые фильтры.

2. С использованием колтюбинговых труб малого диаметра. В этом случае над электроцентробежным насосом может находиться штатный и обычный по своей конструкции обратный клапан, так как растворение и удаление отложений будет происходить по круговой циркуляции по аналогии с тем, как бурят скважины и удаляют гидратные пробки на скважинах по добыче газа и газоконденсата.

Рассмотрим технологии, которые могут быть использованы в нефтедобыче в ближайшее время по обоим этим способам доставки растворителя в зону с отложениями.

Пластовая продукция многих скважин и органический растворитель имеют близкие значения плотности, поэтому датчик давления, установленный над насосом в колонне НКТ, не покажет момент заполнения колонны НКТ реагентом. В связи с этим по изобретению [34] предложено на скважине использовать реперную жидкость, плотность которой будет значимо отличаться от плотности скважинной жидкости. Схема расположения двух датчиков давления над насосом и положение реперной жидкости в колонне лифтовых труб изображены на рис. 1. Скважинная жидкость отделяется от закачиваемого растворителя АСПО высокоминерализованной водой - 13 плотностью 1200 кг/м ${ }^{3}$ небольшого объема (100-200 литров).

Датчики - 3, 4 расположены в первой над насосом трубе повышенного диаметра и соединены с термоманометрической системой - 8. Информация от датчиков поступает с необходимой частотой на станцию управления скважины и на монитор рабочего места технического персонала, который организует удаление отложений в управляемом режиме. На рис. 2 приведена динамика показаний двух датчиков при закачке реперной жидкости и растворителя АСПО. По перепаду давления между датчиками $\Delta \mathrm{P}=\mathrm{P}_{1}-\mathrm{P}_{2}$ на уровне 1,0 атм (точки 2-4) можно судить о гравитационном разделении скважинной продукции на пластовую воду над насосом и нефть с малым содержанием воды (точки 5-6) в верхней части колонны НКТ.

Заполнение колонны НКТ растворителем фиксируется датчиками давления по росту параметра $\Delta \mathrm{P}$ до значения 1,17 атм (точки 7-8) и падением до минимального значения. Линия 9-10 на рис. 2 соответствует поступлению растворителя в электроцентробежный насос.

Рассмотренная технология заполнения колонны НКТ реагентом имеет два положительных эффекта: во-первых, свободное от отложений пространство лифтовых труб заполняется только реагентом, вовторых, одновременно определяется и объем АСПО, по которому определяется объем необходимого органического растворителя. 


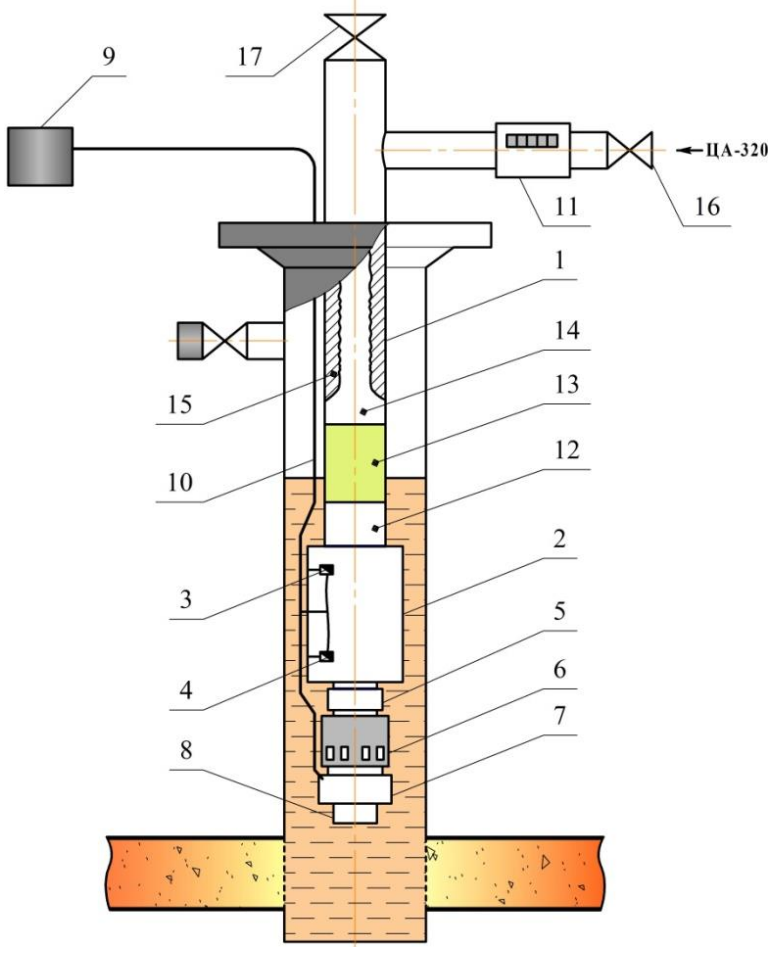

Pис. 1. Диагностика реперной жидкости по двум датчикам давления над насосом: 1 - колонна НКТ; 2 - труба с датчиками давления; 3 - верхний датчик давления; 4 - нижний датчик давления; 5 - КОТ-93; 6 - глубинный электрочентробежный насос; 7 - погружной электродвигатель установки; 8 - термоманометрическая система (TMC); 9 - станция управления скважиной; 10 - электрические кабели подачи электроэнергии и обратной связи от датчиков давления и TMC; 11 - расходомер; 12 - скважинная жидкость; 13 - реперная жидкость; 14 - растворитель АСПО; 15 - отложения в колонне НКТ; 16, 17 - трубопроводные задвижки

Fig. 1. Reference fluid diagnostics using two pressure sensors above the pump: 1 - tubing string; 2 - pipe with pressure sensors; 3 - upper pressure sensor; 4 - lower pressure sensor; 5 - three-position check valve KOT-93; 6 - submersible electric centrifugal pump; 7 - down-hole motor; 8 - thermomanometric system (TMS); 9 - well control station; 10 - pump power cable with reverse information function from pressure sensors and TMS; 11 - flow meter (fluid meter); 12 - borehole fluid; 13 - reference fluid; 14 - ARPD solvent; 15 - deposits in tubing string; 16, 17 - pipe valves

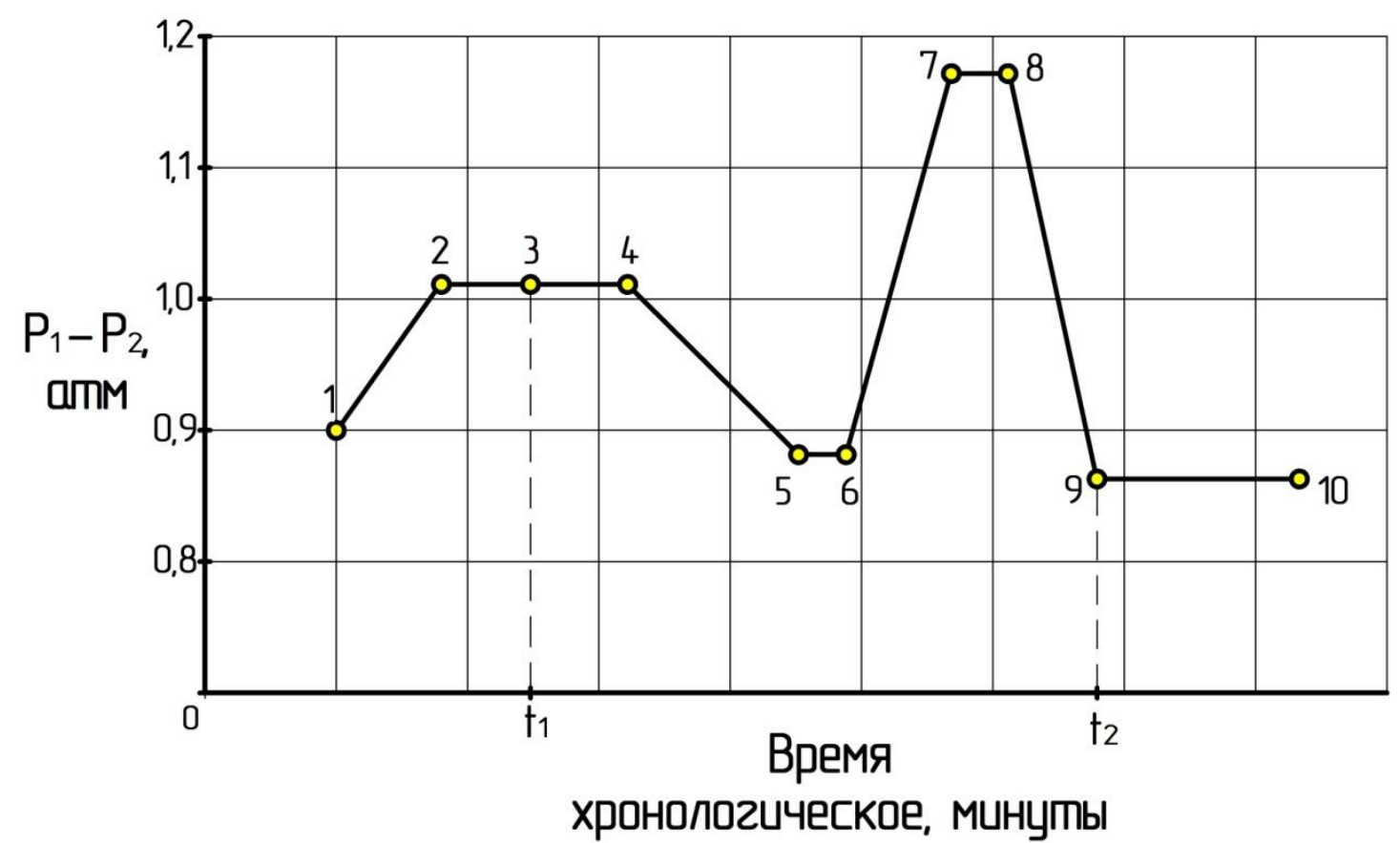

Рис. 2. Оченка плотности жидкости над насосом по датчикам давления: $P_{1}-$ показание нижнего датчика; $P_{2}-n о-$ казание верхнего датчика

Fig. 2. Estimation of liquid density above the pump by pressure sensors: $P_{1}-$ lower sensor reading; $P_{2}-$ upper sensor reading

Опыт применения капиллярных и колтюбинговых труб для адресной доставки реагента в осложненные скважины в зарубежных нефтяных компаниях рассмотрен в работах [35-45]. Трубки используют в скважинах на стационарной основе и для разовых технологических операций различного назначения. К примеру, для постоянного удаления водного и газового конденсата из забойной части газодобывающих скважин применяют капиллярную трубку Ø 3/8 дюйма (9,5 мм). В такую трубку относительно малого диаметра подают реагент для вспенивания конденсатов и их выноса из скважины вместе с газовым потоком [35]. Подача химического реагента по капиллярной трубке в газовую скважину XL (Индонезия) обеспечила высокую эффективность выноса жидкой фазы с продуктивного пласта [36]. Аналогичное ре- 
шение - закачка пенообразователя по капиллярной трубке - впервые было использовано в марте 2010 г. на газовом месторождении Giant Barbara, Италия [37].

Для разовой подачи в призабойную зону пласта реагента - ингибитора или растворителя солевых отложений - через колонну стандартных НКТ с пакерующим устройством спускают колтюбинговую трубу малого диаметра (до 38 мм). Реагент необходимого объема собирают в подпакерном пространстве и продавливают в пласт с помощью технологической жидкости, подаваемой по лифтовым трубам [38]. Наиболее широко реагентные (капиллярные и колтюбинговые) трубки применяются на стационарной и периодической основе для предупреждения гидратообразования в газовых скважинах [39, 40]. В частности, в статье [40] приводится описание процесса растворения гидратов с помощью капиллярной трубки в скважине, эксплуатируемой через плавучую установку для добычи, хранения и отгрузки нефти FPSO в шельфовой зоне Норвегии. В работе [39] приводится описание технологии удаления гидратной пробки через трубку закачивают метанол со скоростью 1-2 галлона в минуту до полного растворения пробки на глубину до 160 футов. В зависимости от диаметра эксплуатационной колонны скорость проникновения трубки в гидратную пробку составляет в среднем 20 футов/ч.

Капиллярные трубки повышенного диаметра 15,8 мм - с успехом используются для удаления парафиновых пробок на глубоководной скважине в Мексиканском заливе [41]. Авторы статьи подчеркивают преимущества трубок малого диаметра в сравнении с колтюбинговыми трубами: насосная часть установки занимает небольшую площадь на платформе, имеет небольшой вес, необходимо меньшее количество обслуживающего персонала, обеспечивается необходимая безопасность труда. С экономической точки зрения авторы работы [42] считают, что капиллярные трубки малого диаметра раза в три привлекательнее, чем колтюбинговые установки.

Электроцентробежная насосная установка скважины конструктивно настроена на движение пластовой жидкости снизу вверх, это обеспечивает отведение тепловой энергии погружного электродвигателя пластовой продукцией с более низкой температурой. Направление движения жидкости на приемные отверстия ЭЦН меняется на противоположное в следующих случаях функционирования системы «пластскважина-насос»:

1. Поступление горячей нефти или растворителя АСПО в межтрубное пространство скважины. Давление в призабойной зоне пласта (ПЗП) повышается, приток флюидов из пласта ослабевает, поэтому насос отбирает сверху недостающую часть жидкости, имеющей пониженные значения теплоемкости и теплопроводности.

2. Ухудшение фильтрационной характеристики ПЗП скважины из-за формирования асфальтосмолопарафиновых отложений в поровом пространстве пласта.
3. Выбытие из строя перепускного клапана на устье скважины ведет к накоплению попутного нефтяного газа над динамическим уровнем, повышению давления в газовой среде и движению нефти в МП вниз, в сторону насоса.

Во всех рассмотренных ситуациях погружной электродвигатель лишается предусмотренного охлаждения, его температура повышается до критического значения, станция управления отключает энергоснабжение двигателя и работу насоса. Для функционирования электроцентробежной установки при движении нефти по МП сверху вниз необходимо поместить насос и погружной электродвигатель (ПЭД) в цилиндрический кожух с открытым низом. Опыт эксплуатации электроцентробежных насосов с кожухом в скважинах с высоким газовым фактором рассмотрен в статье [34].

При стационарном расположении реагентной трубки в колонне НКТ наличие обратного клапана не позволяет организовать доставку реагента в полость насоса. Такая необходимость вызвана одним из условий эффективного применения реагента, например, деэмульгатор должен равномерно смешаться со скважинной жидкостью в мелко диспергированном состоянии для адсорбции на межфазной поверхности нефти и воды за короткий период времени. На скважинах с АСПО существует необходимость промывки растворителем приемных щелевых фильтров от отложений. Их скопления на фильтре являются местным сопротивлением, которое снижает давление на входе в насос и провоцирует рост содержания свободного газа на первых рабочих колесах насоса.

Техническая необходимость создания новой системы подачи реагента на прием ЭЦН выражается следующими позициями:

1. Внутри колонны НКТ реагентная трубка сохранит свою целостность и прослужит многие годы.

2. В скважинах с ЭЦН и обратным клапаном при подаче реагента по колонне лифтовых труб необходимо обойти клапан и обеспечить поступление реагента на прием насоса.

3. Длина кожуха должна быть достаточной для поступления реагента на прием насоса в товарном виде и одновременно обеспечивать охлаждение погружного электродвигателя при движении нефти сверху вниз при возникновении дисбаланса системы «пласт-скважина-насос» и снижении притока жидкости из продуктивного пласта.

В связи с существующей производственной необходимостью предложен дизайн скважинного оборудования в зоне глубинного насоса, приведенный на рис. 3. Реагентная трубка -3 с утяжелителем -4 спускается с устья скважины по колонне НКТ до электромагнитного соединения и надежно соединяется с клапаном-переводником - 7, расположенным в верхней части кожуха-контейнера - 14.

Подаваемый по трубке реагент через радиальные каналы переводника - 7 (разрез А-А) попадает в кольцевое пространство между корпусом насоса и кожуха-контейнера - 14. Значительный диаметр трубки (до 25 мм) дает возможность подавать на при- 
ем насоса реагенты двух видов: ингибиторы - для предупреждения осложнений и растворители - на тот случай, если осложнения в виде сформировавшихся отложений все же наступили. Электромагнитное со- единение и, наоборот, разъединение реагентной трубки и переводника выполняется через термоманометрическую систему - 17 и станцию управления скважины -15 .

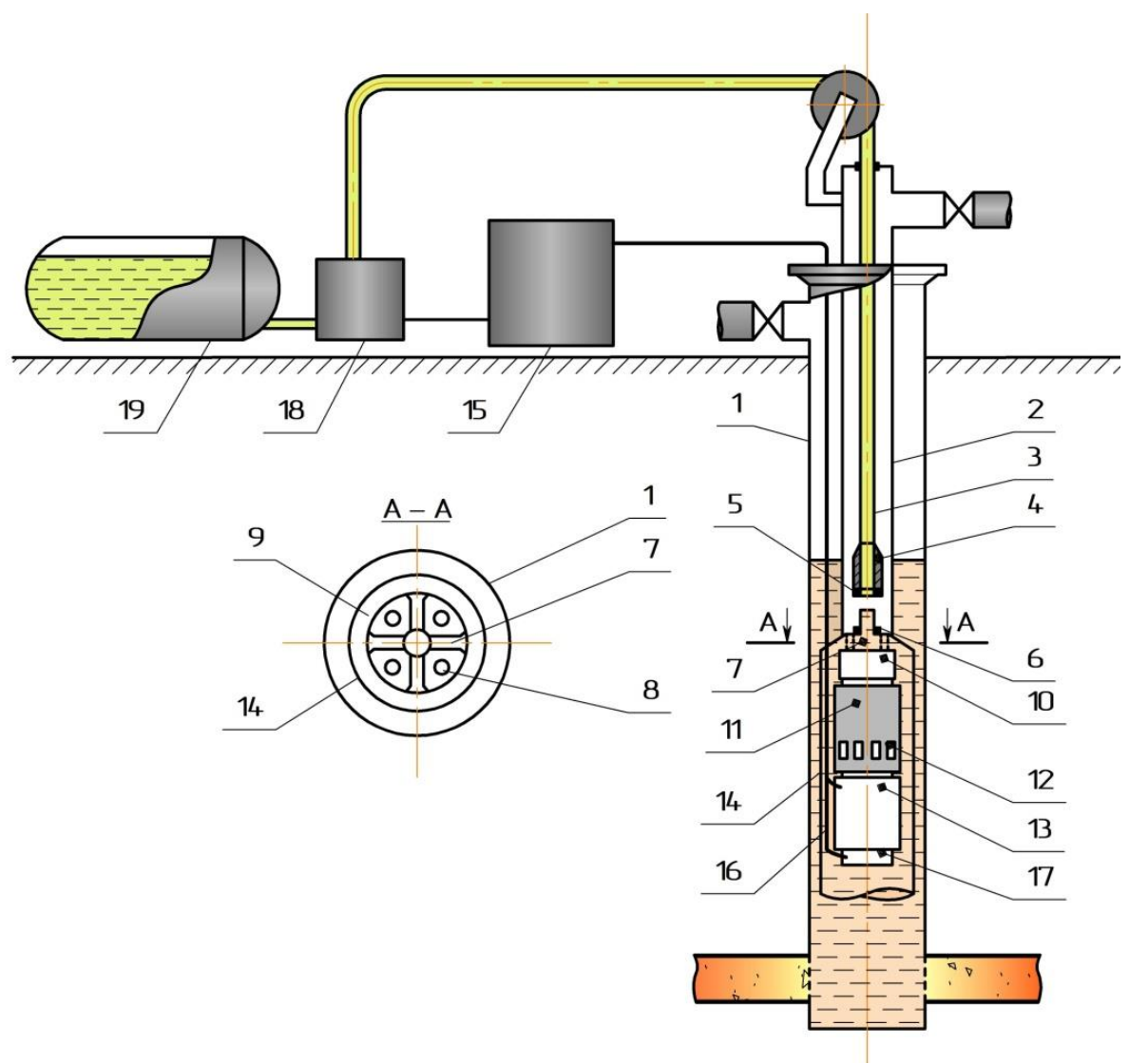

Рис. 3. Схема закачки реагентов по трубке в колонне НКТ на прием насоса: 1 - эксплуатационная колонна; 2 - колонна подъемных труб; 3 - реагентная трубка; 4 - утяжелитель; 5, 6 - электромагнитное соединение; 7 - переводник с радиальными каналами в кольцевое пространство; 8 - каналь для перевода флюидов из насоса в колонну НКТ; 9 - кольцевое пространство между насосом и кожухом; 10 - обратный клапан; 11 - ЭЦН; 12 - приемный фильтр насоса; 13 - электродвигатель; 14 - кожух; 15 - станция управления скважины; 16 - кабель питания электродвигателя и управления соединения 5 и 6; 17 - ТМС; 18 - поверхностный насос; 19 - емкость с реагентом

Fig. 3. Scheme of reagents delivery from the wellhead to the pump intake through a reagent tube in a tubing string: 1 casing; 2 -tubing string; 3 - reagent tube; 4 -weighted bottom of the tube; 5, 6 - electromagnetic connection; 7 - valve-sub with radial channels into the annulus; 8 - channels (4 pieces) for transferring fluids from the pump to the tubing string; 9 - annular space between the pumping unit and the container casing; 10 - back pressure valve; 11 - electrical submersible pump (ESP); 12 - suction eye; 13 - motor driver; 14 - container casing; 15 - well control station; 16 - motor power cable and control connections 5 and 6; 17 - thermomanometric system (TMS); 18 - wellhead pump; 19 - container with reagent

Приведенная на рис. 3 схема подачи реагентов на прием ЭЦН имеет необходимую универсальность - в равной степени можно подавать и ингибиторы с малой суточной дозировкой, и органический растворитель значительного объема. По этой схеме организовано круговое движение реагента внутри колонны НКТ - вниз по реагентной трубке, а вверх - через рабочие колеса и направляющие аппараты насоса и кольцевое пространство в полости колонны лифтовых труб.

Пропускная способность реагентной трубки - 3 уступает производительности любого электроцентробежного насоса, поэтому для сбора растворителя товарного качества на приеме насоса необходимо кон- структивно предусмотреть трубчатый контейнер объемом 500-600 литров. Схема хвостовика с функцией контейнера изображена на рис. 4. Хвостовик выполняет дополнительную функцию - обеспечивает работу ЭЦН даже при снижении уровня жидкости при аварийном выходе из строя обратного клапана для выпуска ПНГ в систему нефтесбора. Из множества равномерно распределенных по длине хвостовика электромагнитных клапанов пропускает в хвостовик и далее на прием насоса лишь один из клапанов. Это регулирует станция управления скважиной по критерию - минимально допустимое расстояние по вертикали от динамического уровня жидкости до действующего клапана. 


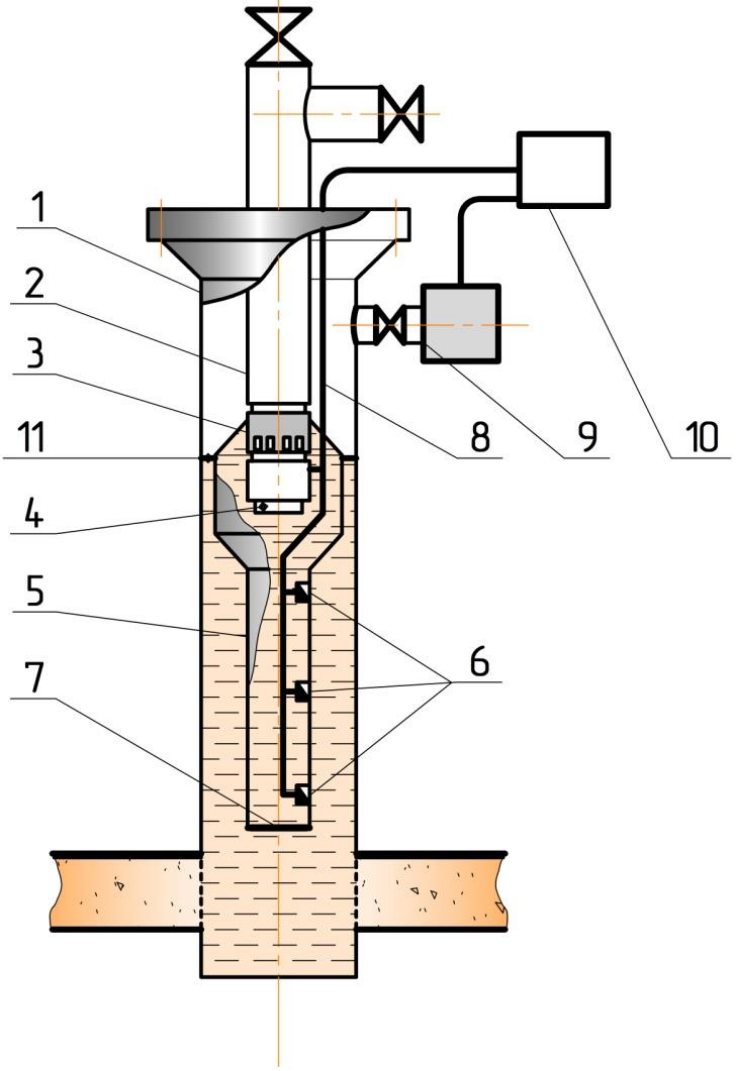

Puc. 4. Схема эксплуатаџии скважины с УЭЦН с кожухом и хвостовиком с впускными клапанами: 1 - эксплуатационная колонна; 2 - подьемные трубы выше насоса; 3 - ЭЦН с погружным электродвигателем; 4 - ТМС; 5 - хвостовик; 6 - электромагнитные клапаны; 7 - заглушка; 8 - кабель электропитания ПЭД, магнитных клапанов и обратной связи от датчиков ТМС ЭЦН; 9 - стационарный уровнемер; 10 - станичя управления скважины; 11 - уровень жидкости в МП скважинь

Fig. 4. Well operation diagram with ESP with casing and stank with filling valves: 1 - casing; 2 - tubing string above the pump; 3 - electrical submersible pump with downhole motor; 4 - thermomanometric system of ESP; 5 - stank below the pump; 6 magnet valves; 7 - blank plug; 8 - power supply cable for the SEM, solenoid valves and feedback from TMS ESP sensors; 9 - stationary level glass; 10 - well control station; 11 -dynamic level of a well

\section{Выводы}

Выполнен анализ источников литературы по применяемым в нефтедобывающей промышленности технологиям доставки реагентов в скважинную зону с отложениями с целью их удаления. Выполнена работа над дизайном скважинного оборудования для рациональной доставки химического реагента на прием

\section{СПИСОК ЛИТЕРАТУРЫ}

1. Крупин Г.Г. Комплексный подход к удалению АСПО в добывающих скважинах Кыртаельского месторождения // Инженерная практика. - 2017. - № 3. - С. 16-17.

2. Филин В.Н. Методы снижения влияния осложняющих факторов при эксплуатации осложненного фонда в ООО «ЛукойлКоми» // Инженерная практика. - 2019. - № 8. - С. 16-24. электроцентробежного насоса. Комплекс выполненных мероприятий позволяет сформулировать следующие выводы по анализируемой теме:

1. Применение органических растворителей для удаления АСПО с подземного оборудования скважин является надежным и экологически выверенным способом продления безаварийной эксплуатации осложненных скважин. Повышение эффективности использования растворителей АСПО базируется на развитии нескольких направлений: на соответствии компонентного состава растворителя составу АСПО, на адресной доставке реагента в зону с отложениями при одновременном сохранении качества реагента на уровне товарных кондиций. Приведенная в статье информация посвящена второму направлению повышения эффективности применения растворителей АСПО.

2. Использование реагентных трубок на стационарной и периодической основе для удаления АСПО, газогидратов, галитов и водного конденсата из газовых скважин нашло широкое применение в нефтяных компаниях по всему миру.

3. Предложена конфигурация подземного оборудования скважины с электроцентробежным насосом для добычи парафинистой и смолистой нефти. Дизайн дополнительного оборудования основан на использовании реагентной трубки внутри колонны лифтовых труб, цилиндрического кожухаконтейнера в зоне насоса и погружного электродвигателя, а также на применении специального клапана для перевода реагента из колонны НКТ в кольцевое пространство между кожухом и корпусом насоса и доведения реагента до приемных отверстий ЭЦН.

4. Авторы статьи считают, что терминология трубок для подачи реагентов в скважинах: «капиллярная» и «колтюбинговая», носит условный характер и допустимо обозначать такие трубки как реагентные. Насколько должен быть большим или малым внутренний диаметр реагентной трубки определяется по формуле Дарси-Вейсбаха исходя из свойств и расхода реагента.

5. При отсутствии на скважине реагентной трубки органический растворитель закачивают по межтрубному пространству или по колонне НКТ. Для исключения неопределенности в объемах закачки дорогостоящего реагента предложено скважину предварительно снабжать датчиками давления и до подачи растворителя в скважину подавать реперную жидкость - высокоминерализованную воду - для уверенной регистрации датчиками давления.

3. Ragunathan T., Husin H., Wood C.D. Wax formation mechanisms, wax chemical inhibitors and factors affecting chemical inhibition // Applied Sciences. - 2020. - V. 10. - № 2. - P. 479.

4. McClaflin G.G., Whitfill D.L. Control of paraffin deposition in production operations // Journal of petroleum technology. 1984. - V. 36. - № 11. - P. 1965-1970. 
5. Struchkov I.A., Roschin P.V. Energy efficiency challenge of waxy oil production by electric submersible pumps // Resource-Efficient Technologies. - 2017. - V. 3. - № 2. - P. 194-197.

6. Sousa A.L., Matos H.A., Guerreiro L.P. Preventing and removing wax deposition inside vertical wells: a review // Journal of Petroleum Exploration and Production Technology. - 2019. T. 9. - № 3. - C. 2091-2107.

7. Мелик-Пашаев В.С. Геология, разведка и разработка нефтяных месторождений. - М.: Недра, 1979. - 334 с.

8. Петрова Л.М. Техногенные изменения свойств углеводородов на поздней стадии разработки нефтяных месторождений // Роль науки при расширении сферы деятельности нефтяников Татарстана. Сборник статей. - Азнакаево: ОАО «Татнефть» им. В.Д. Шашина и Волго-Камское отделение Российской академии естественных наук, 2008. - С. 107-113.

9. Нефтепромысловая химия: Осложнения в системе пластскважина-УППН / В.Н. Глущенко, М.А. Силин, О.А. Пташко, А.В. Денисова. - М.: МАКС Пресс. 2008. - 328 с.

10. Обзор технологий для предотвращения образования АСПО в скважинах Первомайской группы месторождений ПАО «Оренбургнефть» / Е.А. Круглов, Д.В. Лыков, А.П. Баряев, Д.А. Осипов, Н.А. Галиев, А.Ф. Абдуллин // Инженерная практика. - 2017. - № 4. - С. 14-16.

11. Устькачкинцев Е.Н., Мелихин С.В. Определение эффективности методов предупреждения асфальтосмолопарафиновых отложений // Вестник Пермского национального исследовательского политехнического университета. Геология. Нефтегазовое и горное дело. - 2016. - Т. 15. - № 18. - С. 61-70.

12. Иванова Л.В., Буров Е.А., Кошелев В.Н. Асфальтосмолопарафиновые отложения в процессах добычи, транспорта и хранения // Электронный научный журнал «Нефтегазовое дело». 2011. - № 1. - C. 268-284.

13. Paraffin deposition in oil production. Oil composition and paraffin inhibitors activity / M.C. Garcia, L. Carbognani, A. Urbina, M. Orea // Petroleum science and technology. - 1998. - V. 16. № 9-10. - P. 1001-1021.

14. Review of solvents based on biomass for mitigation of wax paraffin in Indonesian oilfield / M.K. Afdhol, M. Abdurrahman, F. Hidayat, F.K. Chong, H.F. Mohd Zaid // Applied Sciences. 2019. - V. 9 - № 24 - P. 5499

15. Осложнения в нефтедобыче / Н.Г. Ибрагимов, А.Р. Хафизов, В.В. Шайдаков, Ф.Р. Хайдаров, А.В. Емельянов, М.В. Голубев, Л.Е. Каштанова, К.В. Чернова, Д.Е. Бугай, А.Б. Лаптев. - Уфа: Монография, 2003. - 302 c

16. Акрамов Т.Ф., Яркеева Н.Р. Борьба с отложениями парафиновых, асфальтосмолистых компонентов нефти // Нефтегазовое дело. - 2017. - Т. 15. - № 4. - С. 67-72.

17. Галикеев И.А., Насыров В.А., Насыров А.М. Эксплуатация месторождений нефти в осложненных условиях. - Ижевск: ООО «Парацельс Принт», 2015. - 354 с.

18. Investigations of temperature and dilution effect on rheological properties of waxy crude oil / I.A. Struchkov, P.V. Roschin, V.T. Litvin, V.A. Ol'hovskaya, E.S. Kalinin // Journal of Petroleum Exploration and Production Technology. - 2020. V. 10, - № 2. - P. 755-767.

19. A critical review of controlling paraffin deposition in production lines using chemicals / Y. Chi, J. Yang, C. Sarica, N. Daraboina // Energy \& fuels. - 2019. - V. 33. - № 4. - P. 2797-2809.

20. Персиянцев М.Н. Добыча нефти в осложненных условиях. М.: ООО «Недра-Бизнесцентр», 2000. - 653 с.

21. Hao L.Z., Al-Salim H.S., Ridzuan N. Review of the mechanism and role of wax inhibitors in the wax deposition and precipitation // Pertanika Journal of Science \& Technology. - 2019. - V. 27. - № 1.

22. Гарифуллин И.Ш. Эффективность применения специального погружного кабельного устройства для предупреждения асфапьтосмолопарафиновых отложений в скважинах // Нефтяное хозяйство. - 2005. - № 12. - С. 92-95.

23. Чертовских Е.О., Салихов Р.М. Альтернативные решения проблемы галито- и гипсообразования при добыче нефти в Восточной Сибири // Инженерная практика. - 2017. - № 4. C. $38-46$.

24. Тороп О.В. Опыт эксплуатации добывающих скважин РУП «Производственное объединение «Белоруснефть» в осложненных условиях по причине выпадения хлоридных солей // Инженерная практика. - 2020. - № 1. - С. 12-18.
25. Jennings D.W., Breitigam J. Paraffin inhibitor formulations for different application environments: from heated injection in the desert to extreme cold arctic temperatures // Energy \& fuels. 2010. - V. 24. - № 4. - P. 2337-2349.

26. Прокудин А.В. Внедение технологий защиты глубиннонасосного оборудования на месторождениях ООО «ЛукойлЗападная Сибирь» // Инженерная практика. - 2019. - № 8. C. 4-9.

27. Денисламов И.З., Гафаров Ш., Галимов А.М. Эффективность применения растворителей АСПО на нефтедобывающих скважинах // Проблемы сбора, подготовки и транспорта нефти и нефтепродуктов. - 2013. - № 1 (91). - С. 53-62.

28. Минеев Б.П., Болигатова О.В. Два вида парафина, выпадающего на подземном оборудовании скважин в процессе добычи нефти // Нефтепромысловое дело. - 2004. - № 12. - С. 41-43.

29. Разработка нефтяных месторождений: Издание в 4-х т. Т. II. Эксплуатация добывающих и нагнетательных скважин / под ред. Н.И. Хисамутдинова, Г.З. Ибрагимова. - М.: ВНИИОЭНГ, 1994. $-273 \mathrm{c}$

30. Мищенко И.Т., Леонов И.В. Основы физико-математической модели системы «эксплуатационный объект-добывающая скважина-установка ЭЦН // Вестник Ассоциации буровых подрядчиков. - 2011. - № 3. - С. 36-40.

31. Денисламов И.З., Гафаров Ш.А., Еникеев Р.М. Интерпретация данных современной телеметрии скважинных электроцентробежных насосов // Нефтегазовые технологии и новые материалы. Проблемы и решения. - Уфа: ООО «Монография», 2014. - C. $243-250$

32. Борьба с отложениями парафина при добыче нефти / С.Ф. Люшин, В.А. Рассказов, Д.М. Шейх-Али, Р.Р. Иксанова, Е.П. Линьков. - М.: Гостоптехиздат, 1961. - 150 с.

33. Каталог продукции НПФ «Пакер». - 2011. - № 10 - С. 106-107. URL: http://www.npf@paker.ru (дата обращения 02.02.2021).

34. Применимость электроцентробежных насосов с кожухом погружного электродвигателя ниже интервала перфорации в скважинах с высоким газовым фактором / В.Е. Еличев, К.В. Ливиненко, А.А. Пустовских, Р.А. Хабибуллин, А.Г. Михайлов, С.Е. Мезиков // Нефтяное хозяйство. - 2009. - № 11. C. $84-87$.

35. Lea J.F., Nickens H.V., Wells M.R. Gas well deliquification. 2nd ed. - New York: Elsevier Press, 2008. - 608 p.

36. Hidayat M.T., Wahid A. Study of chemical injection application with capillary string technique to overcome liquid loading in X1 well, West Java // International Journal of Advances in Science Engineering and Technology. - 2018. - V. 6. - № 3. - P. 70-77.

37. Passucci C., Imbo P., Peoucchi M. Downhole injection of foaming agents with capillary string in a mediterranean offshore gas well // Offshore Mediterranean Conference and Exhibition. - Ravenna, Italy, 2011.

38. Fighting scale: removal and prevention / M.M. Crabtree, D. Eslinger, P. Fletcher, M. Miller, A. Johnson // Oilfield review. - 1999. - V. 11. - № 03. - P. 30-45.

39. Remediation of hydrate plugs in offshore wells via capillary tubing-a cost effective alternative / T.A. Gounah, K. Renfro, J.L. Bolding, M.R. Embrey // SPE Annual Technical Conference and Exhibition. Society of Petroleum Engineers. - Denver, Colorado, USA, 2008.

40. World's first utilization of coiled tubing to dissolve hydrate (s) in an FPSO riser: case history / L.E. Laun, M. Ovesen, H. Varhaug, K.T. Nesvik // SPE/ICoTA Coiled Tubing Conference and Exhibition. Society of Petroleum Engineers. - The Woodlands, Texas, USA, 2005.

41. Embrey M.R., Larke J. Paraffin-plug remediation in deepwater wells via capillary tubing: a cost effective alternative //SPE Annual Technical Conference and Exhibition. Society of Petroleum Engineers. - Florence, Italy, 2010.

42. Innovative use of capillary string for halite cleanout in sultanate of Oman / C. Veeken, A. Alawi, K. Ardia, H. Naabi, N. Janusz, A. Al Abri, H. Ghanem, A. Fadhi, K. Thakur // Abu Dhabi International Petroleum Exhibition \& Conference. Society of Petroleum Engineers. - Abu Dhabi, UAE, 2019.

43. Structure-activity relationship study on paraffin inhibitors for crude oils (INIPAR model II) / M. Cristante, J.L. Selves, G. Grassy, J.P. Colin // Analytica chimica acta. - 1993. - V. 274. № 2. - P. 303-316. 
44. Wilde J., Ellis T. Cementing through capillary tubing to meet regulatory requirements: a novel approach for plug and abandonment //International Petroleum Technology Conference. OnePetro. - Beijing, China, 2013.

45. Embrey M.R., Bolding J.L. Latest Advancements in Capillary Intervention On and Offshore // SPE/ICoTA Coiled Tubing \&
Well Intervention Conference and Exhibition. Society of Petroleum Engineers. - The Woodlands, Texas, USA, 2009.

Поступила 22.09.2021 2.

\section{Информация об авторах}

Денисламов И.З., кандидат технических наук, доцент кафедры разработки и эксплуатации нефтяных и газонефтяных месторождений Уфимского государственного нефтяного технического университета.

Имамутдинова $\boldsymbol{A}$.А., студент кафедры разработки и эксплуатации нефтяных и газонефтяных месторождений Уфимского государственного нефтяного технического университета.

Самушкова Э.С., студент кафедры разработки и эксплуатации нефтяных и газонефтяных месторождений Уфимского государственного нефтяного технического университета. 
UDC 622.276 .72

\title{
TECHNICAL SOLUTIONS FOR REMOVING ASPHALT-RESIN-PARAFFIN DEPOSITS WITH SOLVENTS FROM OIL-PRODUCING WELLS
}

\author{
Ildar Z. Denislamov', \\ denislamoviz@mail.ru
}

\author{
Adelina A. Imamutdinova1, \\ adelina.imamutdinova99@mail.ru \\ Elina S. Samushkova ${ }^{1}$, \\ elinkasamushkova@mail.ru \\ 1 Ufa State Petroleum Technological University, \\ 1, Kosmonavtov street, Ufa, 450062, Russia.
}

The relevance of the study follows from the fact that there is residual oil of increased density with a significant content of heavy components, primarily asphaltenes and resins, in many fields. For many oil companies, there is an increase in the production of wells, the operation of which is complicated by the formation of asphalt-resin-paraffin deposits.

Aims: to perform an overview analysis of the application of methods for preventing and removing asphalt-resin-paraffin deposits in oil fields and to develop an arrangement of underground well equipment based on the use of a reagent tube for delivery of reagents of any type and dosage for receiving an electric submersible pump.

Objects: methods for removing asphalt-resin-paraffin deposits based on the use of organic solvents which are delivered to the intake of a deep pump along the annulus and the tubing. The article discusses all possible options for reagent delivery: two types along the annulus and the same amount along the tubing string.

Methods: based on the laws of physical hydrodynamics, the basics of indicator (reference) technologies and comparative analysis of technical innovations in the world experience of dealing with well deposits.

Results. The authors have substantiated the need to locate the reagent tube inside the tubing string; developed the design of the reagent tube and pumping equipment, which ensures the delivery of any type of reagent to the intake of an electric submersible pump. It was proposed to determine the degree of filling of the tubing string by means of an intermediate - reference - fluid with properties different from borehole fluid and organic solvent. The paper introduces the theory of double oil flow in the annular space to explain the results of factor analysis of the successful delivery of the solvent through the annulus of the well with asphalt-resin-paraffin deposits.

\section{Key words:}

Well, reagent tube, inhibitor, pressure sensor, density, asphalt-resin-paraffin deposits, annulus, reference fluids, organic solvent.

\section{REFERENCES}

1. Krupin G.G. Kompleksny podkhod $\mathrm{k}$ udaleniyu ASPO v dobyvayushchikh skvazhinakh Kyrtaelskogo mestorozhdeniya [Integrated approach to the removal of ARPD in production wells of the Kyrtaelskoe field]. Inzhenernaya praktika, 2017, no. 3, pp. 16-17.

2. Filin V.N. Metody snizheniya vliyaniya oslozhnyayushchikh faktorov pri ekspluatatsii oslozhnennogo fonda v OOO «LukoylKomi» [Methods of reducing the influence of complicating factors during the operation of a complicated fund in OOO Lukoil-Komi] Inzhenernaya praktika, 2019, no. 8, pp. 16-24.

3. Ragunathan T., Husin H., Wood C.D. Wax formation mechanisms, wax chemical inhibitors and factors affecting chemical inhibition. Applied Sciences, 2020, vol. 10, no. 2, pp. 479.

4. McClaflin G.G., Whitfill D.L. Control of paraffin deposition in production operations. Journal of petroleum technology, 1984 vol. 36, no. 11, pp. 1965-1970

5. Struchkov I.A., Roschin P.V. Energy efficiency challenge of waxy oil production by electric submersible pumps. Resource-Efficient Technologies, 2017, vol. 3, no. 2, pp. 194-197.

6. Sousa A.L., Matos H.A., Guerreiro L.P. Preventing and removing wax deposition inside vertical wells: a review. Journal of Petroleum Exploration and Production Technology, 2019, vol. 9, no. 3, pp. 2091-2107.

7. Melik-Pashaev V.S. Geologiya, razvedka i razrabotka neftyanykh mestorozhdeniy [Geology, exploration and development of oil fields]. Moscow, Nedra Publ., 1979. 334 p

8. Petrova L.M. Tekhnogennye izmeneniya svoystv uglevodorodov na pozdney stadii razrabotki neftyanykh mestorozhdeniy [Technogenic changes in the properties of hydrocarbons at the late stage of development of oil fields]. Rol nauki pri rasshirenii sfery deyatelnosti neftyanikov Tatarstana. Sbornik statey [The role of science in expanding the scope of activities of oil workers in Tatarstan. Digest of articles]. Aznakaevo, JSC TATNEFT named after V.D. Shashin and the Volga-Kama branch of the Russian Academy of Natural Sciences Publ., 2008. pp. 107-113.

9. Glushchenko V.N., Silin M.A., Ptashko O.A., Denisova A.V. Neftepromyslovaya khimiya: oslozhneniya $v$ sisteme plastskvazhina-UPPN [Oilfield chemistry: complications in the reservoir-well-OPPU system]. Moscow, MAKS Publ. 2008. 328 p.

10. Kruglov E.A., Lykov D.V., Baryaev A.P., Osipov D.A., Galiev N.A., Abdullin A.F. Obzor tekhnologiy dlya predotvrashcheniya obrazovaniya ASPO $\mathrm{v}$ skvazhinakh Pervomayskoy gruppy mestorozhdeniy PAO «Orenburgneft» [Review of technologies for preventing the formation of ARPD in the wells of the Pervomaiskaya group of fields of PJSC «Orenburgneft»]. Inzhenernaya praktika, 2017, no. 4, pp. 14-16.

11. Ustkachkintcev E.N., Melekhin S.V. Determination of the efficiency of wax deposition prevention methods. Bulletin of the Perm National Research Polytechnic University. Geology. Oil and gas engineering and mining, 2016, vol. 15, no. 18, pp. 61-70. In Rus.

12. Ivanova L.V., Burov E.A., Koshelev V.N. Asphaltene-resinparaffin deposits in the processes of oil production, transportation and storage. Electronic scientific journal «Oil and Gas Business», 2011, no. 1, pp. 268-284. In Rus.

13. Garcia M.C., Carbognani L., Urbina A., Orea M. Paraffin deposition in oil production. Oil composition and paraffin inhibitors activity. Petroleum science and technology, 1998, vol. 16, no. 9-10, pp. 1001-1021.

14. Afdhol M.K., Abdurrahman M., Hidayat F., Chong F.K., Mohd Zaid H.F. Review of Solvents Based on Biomass for Mitigation of Wax Paraffin in Indonesian Oilfield. Applied Sciences, 2019, vol. 9 , no. 24, pp. 5499. 
15. Ibragimov N.G., Khafizov A.R., Shaydakov V.V., Khaydarov F.R., Emelyanov A.V., Golubev M.V., Kashtanova L.E., Chernova K.V., Bugay D.E., Laptev A.B. Oslozhneniya $v$ neftedobyche [Complications in oil production]. Ufa, Monograph Publ., 2003. $302 \mathrm{p}$.

16. Akramov T.F., Iarkeeva N.R. Control deposits of paraffin, asphaltresin components of oil. Oil and Gas Business, 2017, vol. 15, no. 4, pp. 67-72. In Rus.

17. Galikeev I.A., Nasyrov V.A., Nasyrov A.M. Ekspluatatsiya mestorozhdeniy nefti $v$ oslozhnennykh usloviyakh [Operation of oil fields in difficult conditions]. Izhevsk, LLC «Paracelsus Print», 2015. $354 \mathrm{p}$.

18. Struchkov I.A., Roschin P.V., Litvin V.T., Ol'hovskaya V.A. Kalinin E.S. Investigations of temperature and dilution effect on rheological properties of waxy crude oil. Journal of Petroleum Exploration and Production Technology, 2020, vol. 10, no. 2, pp. 755-767.

19. Chi Y., Yang J., Sarica C., Daraboina N. A critical review of controlling paraffin deposition in production lines using chemicals. Energy \& fuels, 2019, vol. 33, no. 4, pp. 2797-2809.

20. Persiyancev M.N. Dobycha nefti v oslozhnennykh usloviyakh [Oil production in difficult conditions]. Moscow, LLC «NedraBusiness Center», 2000. $653 \mathrm{p}$.

21. Hao L.Z., Al-Salim H.S., Ridzuan N. A Review of the Mechanism and Role of Wax Inhibitors in the Wax Deposition and Precipitation. Pertanika Journal of Science \& Technology, 2019, vol. 27, no. 1.

22. Garifullin I.Sh. Efficiency of application of special downhole cable device for prevention of asphalt-resin-wax deposits in wells. Oil industry, 2005, no. 12, pp. 92-95. In Rus.

23. Chertovskikh E.O., Salikhov R.M. Alternativnye resheniya problemy galito- i gipsoobrazovaniya pri dobyche nefti v Vostochnoy Sibiri [Alternative solutions to the problem of halite and gypsum formation during oil production in Eastern Siberia]. Inzhenernaya praktika, 2017, no. 4, pp. 38-46.

24. Torop O.V. Opyt ekspluatatsii dobyvayushchikh skvazhin RUP «Proizvodstvennoe obedinenie "Belorusneft"» v oslozhnennykh usloviyakh po prichine vypadeniya khloridnykh soley [Operating experience of production wells of RUE «Production Association "Belorusneft"»in difficult conditions due to precipitation of chloride salts]. Inzhenernaya praktika, 2020, no. 1, pp. 12-18.

25. Jennings D.W., Breitigam J. Paraffin inhibitor formulations for different application environments: from heated injection in the desert to extreme cold arctic temperatures. Energy \& fuels, 2010 vol. 24, no. 4, pp. 2337-2349.

26. Prokudin A.V. Vnedrenie tekhnologiy zashchity glubinnonasosnogo oborudovaniya na mestorozhdeniyakh $\mathrm{OOO}$ «LukoylZapadnaya Sibir» [Implementation of technologies for protection of downhole pumping equipment at the fields of OOO LukoilWestern Siberia]. Inzhenernaya praktika, 2019, no. 8, pp. 4-9.

27. Denislamov I.Z., Gafarov Sh.A., Galimov A.M. The use of solvents of asphalt-tar-wax depositions at oil wells. Problems of gathering, treatment and transportation of oil and oil products, 2013, no. 1 (91), pp. 53-62. In Rus.

28. Mineev B.P., Boligatova O.V. Two types of paraffin, the dropdown on the downhole equipment in oil production. Oilfield engineering, 2004, no. 12, pp. 41-43. In Rus.

29. Khisamutdinov N.I., Ibragimov G.Z. Razrabotka neftyanyh mestorozhdeniy [Development of oil fields]. Moscow, VNIIOENG Publ., 1994. Vol. 2, 273 p.

30. Mishenko I.T., Leonov I.V. Fundamentals of physicalmathematical model of «development target - producing well ESP» system. Drilling Contractors Association Bulletin, 2011, no. 3, pp. 36-40. In Rus.
31. Denislamov I.Z., Gafarov SH.A., Enikeev R.M. Interpretatsiya dannykh sovremennoy telemetrii skvazhinnyhk elektrotsentrobezhnykh nasosov [Interpretation of modern telemetry data for borehole electric centrifugal pumps]. Neftegazovye tekhnologii i novye materialy. Problemy i resheniya [Oil and gas technologies and new materials. Problems and solutions]. Ufa, OOO «Monografiya» Publ., 2014. pp. 243-250.

32. Lyushin S.F., Rasskazov V.A., Sheykh-Ali D.M., Iksanova R.R. Linkov E.P. Borba s otlozheniyami parafina pri dobyche nefti [Fighting wax deposits in oil production]. Moscow, Gostoptekhizdat Publ., 1961. 150 p.

33. Product catalog of NPF «Packer», 2011, no. 10, pp. 106-107. Available at: http://www.npf@paker.ru (accessed 2 February 2021)

34. Yelichev V.A., Litvinenko K.V., Pustovskikh A.A., Khabibullin R.A. Applicability of electric centrifugal pumps with submersible electric motor casing below the perforated interval in wells with high gas-oil ratio. Oil industry, 2009, no. 11, pp. 84-87. In Rus.

35. Lea J.F., Nickens H.V., Wells M.R. Gas Well Deliquification. $2^{\text {nd }}$ ed. New York, Elsevier Press, 2008. 608 p.

36. Hidayat M.T., Wahid A. Study of chemical injection application with capillary string technique to overcome liquid loading in X1 Well, West Java. International Journal of Advances in Science Engineering and Technology, 2018, vol. 6, no. 3, pp. 70-77.

37. Passucci C., Imbo P., Peoucchi M. Downhole injection of foaming agents with capillary string in a mediterranean offshore gas well. Offshore Mediterranean Conference and Exhibition. Ravenna, Italy, 2011.

38. Crabtree M.M., Eslinger D., Fletcher P., Miller M., Johnson A. Fighting scale: removal and prevention. Oilfield review, 1999, vol. 11 , no. 3, pp. 30-45.

39. Gounah T.A., Renfro K., Bolding J.L., Embrey M.R. Remediation of hydrate plugs in offshore wells via capillary tubing-a cost effective alternative. SPE Annual Technical Conference and Exhibition. Society of Petroleum Engineers. Denver, Colorado, USA, 2008.

40. Laun L.E., Ovesen M., Varhaug H., Nesvik K.T. World's first utilization of coiled tubing to dissolve hydrate (s) in an FPSO riser: case history. SPE/ICoTA Coiled Tubing Conference and Exhibition. Society of Petroleum Engineers. The Woodlands, Texas, USA, 2005

41. Embrey M.R., Larke J. Paraffin-plug remediation in deepwater wells via capillary tubing: a cost effective alternative. SPE Annиal Technical Conference and Exhibition. Society of Petroleum Engineers. Florence, Italy, 2010.

42. Veeken C., Alawi A., Ardia K., Naabi H., Janusz N., Al Abri, A., Ghanem H., Fadhi A., Thakur K. Innovative use of capillary string for halite cleanout in sultanate of Oman. Abu Dhabi International Petroleum Exhibition \& Conference. Society of Petroleum Engineers. Abu Dhabi, UAE, 2019.

43. Cristante M., Selves J.L., Grassy G., Colin J.P. Structure-activity relationship study on paraffin inhibitors for crude oils (INIPAR model II). Analytica chimica acta, 1993, vol. 274, no. 2, pp. 303-316.

44. Wilde J., Ellis T. Cementing through capillary tubing to meet regulatory requirements: a novel approach for plug and abandonment. International Petroleum Technology Conference. OnePetro. Beijing, China, 2013.

45. Embrey M.R., Bolding J.L. Latest advancements in capillary intervention on and offshore. SPE/ICoTA Coiled Tubing \& Well Intervention Conference and Exhibition. Society of Petroleum Engineers. The Woodlands, Texas, USA, 2009.

Received: 22 September 2021.

\section{Information about the authors}

Ildar Z. Denislamov, Cand. Sc., associate professor, Ufa State Petroleum Technological University.

Adelina A. Imamutdinova, bachelor student, Ufa State Petroleum Technological University.

Elina S. Samushkova, bachelor student, Ufa State Petroleum Technological University. 